\title{
CORRESPONDENCE
}

\section{Sedation in a patient with William Syndrome without supravalvular aortic stenosis and normal QT: Challenge still remains}

\author{
Roma Sharma, Habib Md Reazaul Karim, Omer Mohammed Mujahid, Rahul Kanjilal \\ Department of Anaesthesiology and Critical Care, All India Institute of Medical Sciences Raipur, India. \\ Correspondence: Dr Habib Md Reazaul Karim; e-mail: drhabibkarim@gmail.com \\ Citation: Sharma R, Karim HMR, Mujahid OM, Kanjilal R. Sedation in a patient with William Syndrome without supravalvular \\ aortic stenosis and normal QT: Challenge still remains. Anaesth. pain intensive care 2020;24(3):363-365.
}

Keywords: Anesthesia; Sedation; William Syndrome; Hemodynamics; Anesthesia outside Operating Room

\section{Dear Editor,}

William Syndrome (WS) is a rare genetic condition related to deletion of elastin gene resulting in distinctive facies, cardiovascular diseases, learning difficulties, developmental delay, unique personality characteristics, endocrine involvement, etc. ${ }^{1}$ Although successful anaesthesia is reported, literature review indicate significant major adverse cardiac events (MACE) including sudden death, as frequent. ${ }^{2}$ So anaesthetic management of these patients has proved to be challenging. The cardiovascular abnormality, corrected QT, and cardio-depressant actions of anaesthetic drugs need critical considerations. ${ }^{2}$ Further, effect of mild to moderate sedation for interventions outside operating room in such patients are not much known. With the advancement of anaesthesia techniques and drugs, whether the cardiovascular response of such patient remains the same, continues to be a query.

A 7-year-old boy, malnourished, BMI $14.61 \mathrm{Kg} / \mathrm{m}^{2}$, a known case of WS was posted for computed tomography (CT) Aortography and Pulmonary Angiogram. The boy was having typical elfin facies (Figure-1a, 1b). His pulse rate was 105/min, regular; room air saturation $100 \%$ with normal respiration and systolic BP $80 \mathrm{mmHg}$ by palpation (child not cooperative). Ejection systolic murmur grade-3 at Right second intercostal space with normal $S_{1}$ and $S_{2}$ was noted. The child was restless with a history of developmental delay and mental retardation but was able to climb 3-4 flight of stairs without any dyspnea or syncope. The child was primarily planned to undergo circumcision, but, clinical finding directed for further cardiac evaluation. His haemoglobin, electrolytes, resting ECG, and 2-D Echocardiography was normal.

He was on syrup Risperidone and tablet Clonidine orally; instructed to continue the same. With consent and premedication of $1 \mathrm{mg}$ Midazolam, the child was taken to the CT room, and standard monitoring was attached. Further sedation was given with $10 \mathrm{mg}$ (approximate $37.5 \mu \mathrm{g} / \mathrm{Kg} / \mathrm{min}$ ) of propofol IV slowly in a drip over 15 minutes. Oxygen was supplemented, and $\mathrm{BP}$ and $\mathrm{SpO}_{2}$ were stable throughout. $\mathrm{A}$ considerable heart rate (HR) variation from 35 to $70 /$ min (plethysmograph seconded it) during the entire 10 minutes duration of the procedure was noted in ECG. Post-procedure, the patient regained consciousness within 15 minute, and vitals were stable. CT showed the impression of the right-sided aortic arch (figure-1c) with aberrant left subclavian artery originating from Kommerell's diverticulum with the retro-esophagal course, and no aortic and pulmonary artery stenosis (figure-1d).

Patients with WS often require anaesthesia services for various interventions/surgeries. Although $\mathrm{CT}$ is a relatively short procedure and devoid of noise; contrast injection and following commands need a cooperative 
patient. It is usually feasible in younger children without sedation, but, neurobehavioral involvement in patients of WS and environmental anxiety often demand sedation services. On the other hand, SVAS
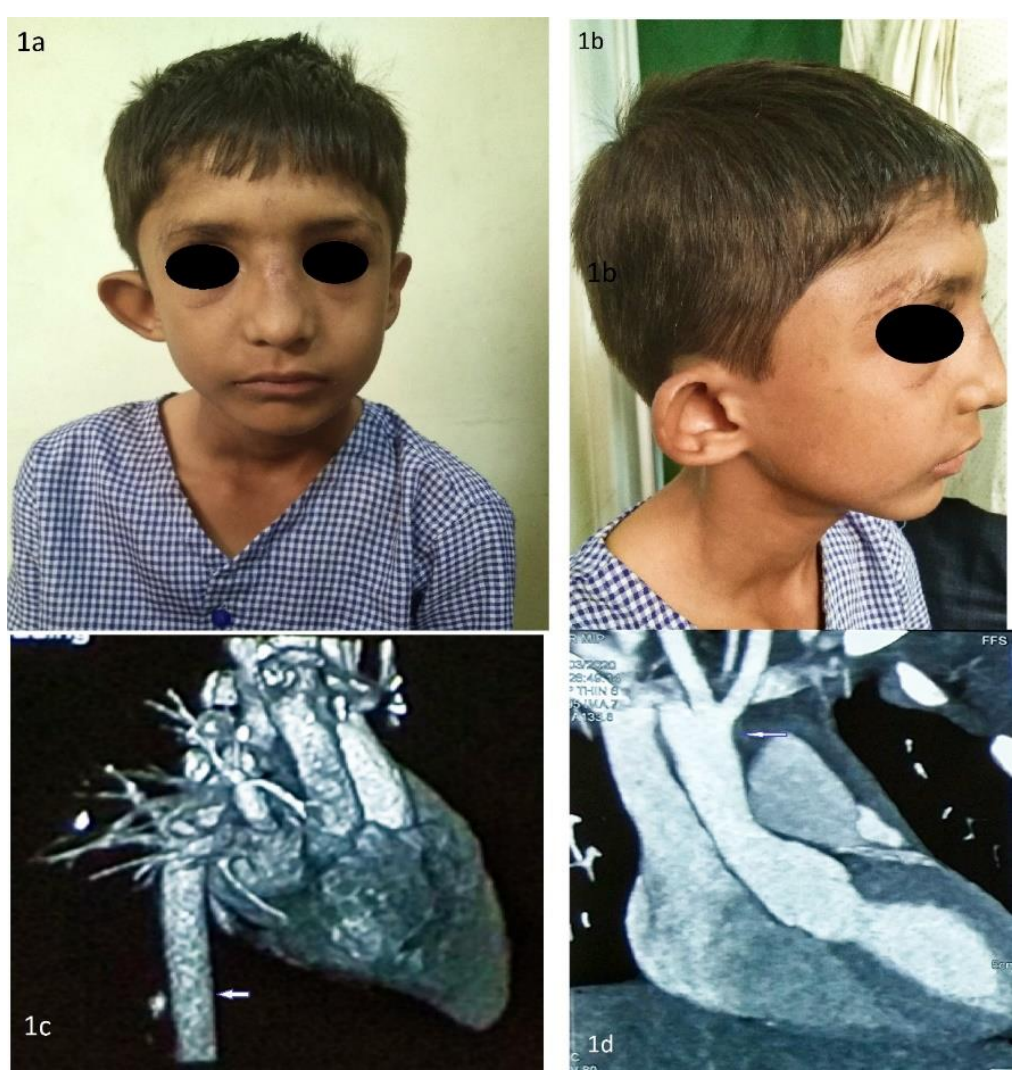

Figure 1: Showing hypertelorism and elfin facies (1a and 1b), right-sided descending aorta (1c), and aberrant left subclavian artery originating from Kommerell's diverticulum with normal supravalvular aortic segment (1d).
Hence, absence of SVAS should not be taken lightly during anaesthesia and/or sedation.

Secondly, history suggestive of intermediate level metabolic equivalents of tasks might not be genuinely predictive of cardiac events. So, vigilance and preprocedural cardiovascular evaluation might be considered even when the patient is posted for minor procedures. Thirdly, monitoring like ECG is often interfered, especially in MRI. In such a situation, plethysmograph should be considered along with ECG tracing. Absence of any one might compromise patient safety even for mild sedation in patients with WS. Invasive blood pressure for a beat to beat variability may be required when the procedure is expected to last long. Further, prolonged corrected QT (QTc) can also be the reason for MACE, however, it is to be noted that prolonged QTc is found in only $13 \%$ of WS patients. ${ }^{7}$

Fourthly, the risk involved with sedation and benefit from the procedure should be weighed before planning any intervention or surgery. Even a minor procedure planned to be done under mild to moderate sedation needs explaining, and informed documented consent for major cardiac events in patients with WS.

Conflicts of interests: None predisposes the patient to reduced coronary perfusion, and resulting demand-supply mismatch under anaesthesia is considered as the pathophysiology of cardiovascular complications and fatality. ${ }^{3,4} \mathrm{~A}$ recent study indicates that the risk can be mitigated with proper planning and hemodynamic management goals in patients with WS undergoing non-cardiac surgeries. ${ }^{5}$

The present case, although did not have a fatality, taught us a few lessons. Firstly, WS patient without SVAS is also prone for MACE. Although cardiovascular involvement is the most common and nearly $80 \%$ of the patients has structural cardiovascular abnormality; supravalvular aortic stenosis (SVAS) is found in $45-75 \%$ of the patients. ${ }^{6}$

\section{References}

1. Morris CA. Williams Syndrome. In: Adam MP, Ardinger HH, Pagon RA, et al. (eds.) GeneReviews ${ }^{\circledR}$. Seattle (WA): University of Washington, Seattle; 1993-2020. Available from: https://www.ncbi.nlm.nih.gov/books/NBK1249/

2. Matisoff AJ, Olivieri L, Schwartz JM, Deutsch N. Risk assessment and anesthetic management of patients with Williams syndrome: a comprehensive review. Paediatr Anaesth. 2015 Dec;25(12):1207-1215. [PubMed] DOI: 10.1111/pan.12775

3. Burch TM, McGowan FX Jr, Kussman BD, Powell AJ, DiNardo JA. Congenital supravalvular aortic stenosis and sudden death associated with anesthesia: What's the mystery? Anesth Analg. 2008;107:1848-1854. [PubMed] DOI: $10.1213 / a n e .0 b 013 e 3181875 a 4 d$ 
4. Gupta P, Tobias JD, Goyal S, Miller MD, Melendez E, Noviski N, et al. Sudden cardiac death under anesthesia in pediatric patient with Williams syndrome: a case report and review of literature. Ann Card Anaesth. 2010;13:4448. [PubMed] DOI: 10.4103/0971-9784.58834

5. Brown ML, Nasr VG, Toohey R, DiNardo JA. Williams syndrome and anesthesia for non-cardiac surgery: High risk can be mitigated with appropriate planning. Pediatr Cardiol. 2018;39:1123-1128. [PubMed] DOl: 10.1007/s00246-018-1864-1

6. Collins RT 2nd. Cardiovascular disease in Williams syndrome. Circulation. 2013;127:2125-2134. [PubMed] DOI: 10.1161/CIRCULATIONAHA.112.000064

7. Collins RT. Clinical significance of prolonged QTc interval in Williams syndrome. Am J Cardiol. 2011;108(3):471-473. [PubMed] DOI: 10.1016/j.amjcard.2011.03.071 
